\title{
The Role of Futureproofing in the Management of Infrastructural Assets
}

Tariq Masood, Duncan McFarlane, Jennifer Schooling and Ajith Parlikad Institute for Manufacturing \& Centre for Smart Infrastructure \& Construction Department of Engineering, University of Cambridge, Cambridge, United Kingdom

\section{ABSTRACT}

Ensuring long-term value from infrastructure is essential for a sustainable economy. In this context, futureproofing involves addressing two broad issues:

i. Ensuring the ability of infrastructure to be resilient to unexpected or uncontrollable events e.g. extreme weather events; and

ii. Ensuring the ability to adapt to required changes in structure and / or operations of the infrastructure in the future e.g. expansion of capacity, change in usage mode or volumes.

Increasingly, in their respective roles, infrastructure designers/builders and owners/operators are being required to develop strategies for futureproofing as part of the life cycle planning for key assets and systems that make up infrastructure.

In this paper, we report on a preliminary set of studies aimed at exploring the following issues related to infrastructure / infrastructure systems:

- What is intended by the futureproofing of infrastructural assets?

- Why and when to futureproof critical infrastructure?

- How can infrastructure assets and systems be prepared for uncertain futures?

- How can futureproofing be incorporated into asset management practice?

In order to seek answers to the above questions, the Cambridge Centre for Smart Infrastructure and Construction (CSIC) has conducted two industrial workshops bringing together leading practitioners in the UK infrastructure and construction sectors, along with government policy makers. This paper provides an initial summary of the findings from the workshops (part presentation, part working sessions), and proposes a simple framework for linking futureproofing into broader asset management considerations.

To begin, an overview of futureproofing and motivate the need for futureproofing infrastructure assets is provided. Following this, an approach to futureproofing infrastructure portfolios is presented that organisations in the infrastructure sector can use. Key barriers to futureproofing are also presented before examining the ISO 55001 asset management standard to highlight the interplay between futureproofing and infrastructural asset management. Finally, different ways by which an effective futureproofing strategy can enhance the value of infrastructure are examined.

Keywords: Infrastructure, Futureproofing, Asset Management, Resilience, Change Management Capability 


\section{WHAT IS INFRASTRUCTURAL FUTUREPROOFING?}

For the purposes of this study infrastructure futureproofing has been defined as "the process of making provision for future developments, needs or events that impact on particular infrastructure through its current planning, design, construction or asset management processes".

Having examined the different industrial motivations for futureproofing in an infrastructure context, there are two distinct considerations:

i. Infrastructural Resilience: By this we refer to the resilience of critical infrastructure in the face of unexpected / uncontrollable events and circumstances. This might include ability to withstand climate change variations, flooding events or even terrorist actions.

ii. Change Management Capability: Here we refer to the capability of critical infrastructure to adapt or respond to changing needs, uses or capacities. Examples of futureproofing in this context might include easier reuse of substructure elements and buried structures, allowing infrastructure life to be extended, such as by 'bolting on extra lanes on a bridge', or by building more floors on an existing building.

\section{WHY IS CONSIDERATION OF FUTUREPROOFING NECESSARY?}

There is significant evidence emerging that consideration of the future needs of infrastructure is the only responsible path to follow in the development and maintenance of infrastructure. Such consideration may conclude that a 'no action' response is the most cost effective long term strategy - e.g. in the acceptance that some assets may need to be sacrificed under particular flood scenarios - but we differentiate here between no consideration and no action. The latter is a conscious decision based on an economic /social / strategic analysis of the role of the selected asset. The following paragraphs outline some of the evolving debates around the need for managing future scenarios for critical infrastructure carefully and thoroughly.

The UK national infrastructural assets generally have long operational lifetimes and majority of the UK's existing infrastructure was originally built in the 19th century e.g. London's sewerage system and Royal Albert Bridge over the River Tamar'. Unplanned and uncontrolled user driven future changes to infrastructure and infrastructure systems are also required to be made during operations e.g. design changes, adaptability / capacity changes, and need changes. The consequences of such disruptions and changes are huge over long infrastructure life cycles, which lead to futureproofing considerations. Increase in population also adds to the infrastructure capacity issues over long life cycles.

Not only is infrastructure required to last longer, but recently there has been increase in disruptive extreme events due to climate changes e.g. heavy snowfalls in the UK in 2010 affected transport infrastructure particularly rail and airports. A number of road bridges collapsed and the road and rail networks were disrupted during 2009-2014 as a result of severe flooding. Key climate change impacts are identified as increased flooding (fluvial, tidal and pluvial or surface water), high temperatures (extreme weather events) and increased water scarcity ${ }^{2}{ }^{3}$. Extreme weather (e.g. heavy rainfall pluvial flooding, wind storms, snow, and ice) also poses construction risks. Flooding also causes operational risks. High ambient temperatures affect rolling stock and railway tracks as well as passenger comfort.

Hurricanes, earthquakes, drought threats and resource scarcity are among other disruptions to infrastructure or infrastructure systems due to long term climate change effects. This means that such infrastructure needs to be maintained for the long term with future climate changes in mind i.e. making it resilient and more adaptable, key challenges identified by DEFRA as for climate resilient infrastructure'.

Other reasons to consider futureproofing include the following: wider social, economic and environmental benefits are particularly important for infrastructure with high vulnerability and lower capacity to respond to risks (Atkins, UCL and DFID 2012); interconnected risk topologies are key for energy intensive infrastructure with significant carbon footprint, major climate hazards, regional support systems such as water and food systems, and multiple risks e.g. risks of

1 DEFRA (2011) "Climate Resilient Infrastructure: Preparing for a Changing Climate", pp 1-76, available from www.defra.gov.uk/ environment/climate/sectors/infrastructure-companies/.

2 RSSB (2011) "Operations and Management: Adapting to extreme climate change (TRaCCA), Phase 3 report - Tomorrow's railway and climate change adaptation (T925 Report)

3 Paris, R. (2011) "Crossrail-Climate Change Adaptation", Crossrail presentation. 
disaster, earth quakes ${ }^{4}$; foresights projections for solutions for future infrastructure can change over long time periods and may include considering flexible structures, having sustainable resources, reactive facades, and smart systems ${ }^{5}$.

This growing set of drivers for a more formal and considered approach to managing the future of critical infrastructure is discussed in the following section.

\section{AN APPROACH TO FUTUREPROOFING OF INFRASTRUCTURE}

As part of the outputs from the series of workshops relating to infrastructural futureproofing, a simple approach to futureproofing of infrastructure has been developed. This approach (which could possibly become a framework) is intended to be applicable to a portfolio of an infrastructure e.g. a county's bridges portfolio consisting of 100 s of different types of bridges. The approach is presented in Figure 1, and considers the following:

\section{Requirements Analysis}

In order to identify and understand user needs and the requirements of business and external parties, stakeholder and PESTLE (Political, Economic, Social, Technological, Legal, and Environmental) analyses are conducted. Stakeholder examples include public, asset owners, asset operators, asset maintainers, organisations e.g. utility companies, regulatory bodies, interdependent and mutually benefited companies, UK Government, Infrastructure UK, treasury, investors, and the media. The PESTLE analysis will answer questions related to key political drivers of relevance, important economic factors, treasury rules and budget availability, main societal and cultural aspects, current technological imperatives, changes and innovations, current and impending legislation and environmental considerations affecting the infrastructure.

\section{Futureproofing Considerations}

There are a number of futureproofing considerations that need to be considered for long term sustainability of infrastructure. These range from developing meaningful and implementable criteria, strategies, technological solutions, options appraisal, information continuity, anticipated asset life, supporting lifecycle models, risks of not futureproofing, future scenarios, impact and criticality of infrastructure or infrastructure systems and elements.

The following set of criteria is proposed for considering infrastructure futureproofing requirements, strategies and solutions:

- Resilience - ability to withstand shocks and recover quickly;

- Adaptability - ability to be readily adapted or reconfigured if understanding of risks or requirements change;

- Replaceability - ability to be replaced during or at the end of life or use;

- Reusability - ability to be reused or extended if no longer required for original purpose; and

- Self-reinforceability - ability to work with, rather than against natural processes

- Organisations would need to consider above mentioned futureproofing elements as well as any additional set of futureproofing considerations in their strategies to plan, design, construct and maintain.

- The following questions are also relevant while considering criteria:

- Quality - What is the quality criteria for infrastructure; and how to measure, monitor and sustain the quality?

- Value - What is the value in optimising and updating the infrastructure?

- Time - How long to optimise and update for?

- Performance - What is the definition of infrastructure performance? How to measure, monitor and sustain it?

- Lifecycle - Which are the key lifecycle stages for the infrastructure?

- Risk - What are the key risks to futureproofing infrastructure and assets?

- Criticality - What is the criticality of various elements of the infrastructure and assets?

- Strategies - Which strategies are relevant in futureproofing the infrastructure?

- Technologies - Which technologies are relevant in futureproofing the infrastructure?

- Information - What types of information are required to support futureproofing decisions? Are those information types collected, maintained, updated and made available for reuse throughout the lifecycle (and even beyond in some cases)?

\footnotetext{
4 Atkins, UCL and DFID (2012) "Futureproofing Cities - Risks and opportunities for inclusive urban growth in developing countries", London, 20 November.

5 Hargrave, J. (2013) "It's Alive! - Can you imagine the urban building of the future?", ARUP Foresight \& Innovation, London, January 2013, pp 1-12
} 


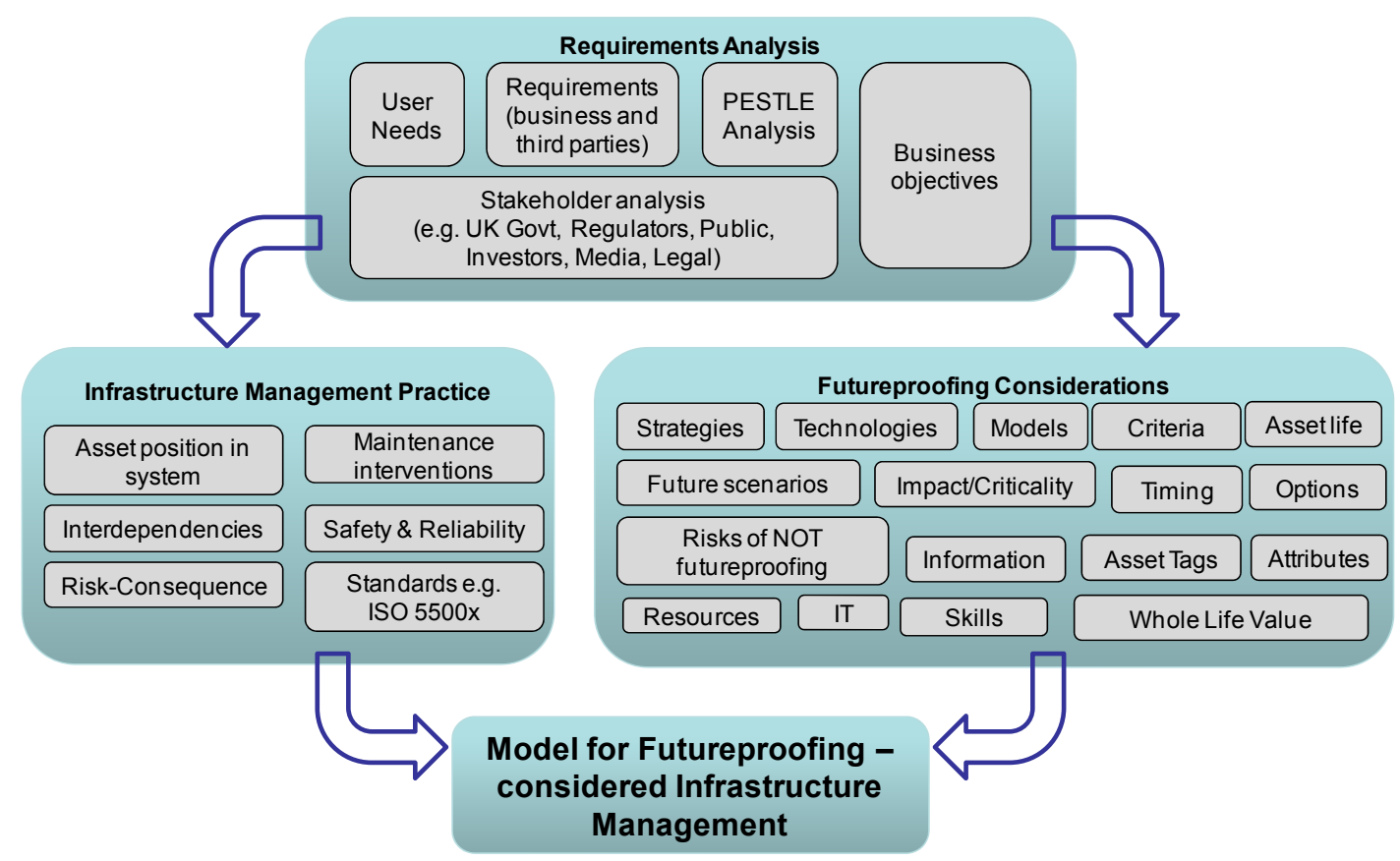

Figure 1: An approach to futureproofing of infrastructure portfolio

\section{Infrastructure Management Practice}

Infrastructure management practice is analysed so that the outputs of futureproofing considerations could be integrated. Key related questions follow:

- Interdependencies - How different assets comprising the infrastructure are interdependent?

- Asset Position in System - What are different systems providing functionalities of the infrastructure? What are the asset positions in those systems?

- Standards - Which standards are (being) implemented e.g. PAS 55, ISO 55001:2014, and BS 1192-3? What are the key lessons learnt from their implementation? What are the key interfaces?

- Safety \& reliability - How safe and reliable is the infrastructure? What are the threats and challenges?

- Risk-Consequences - What are the risks prone to the infrastructure and assets? What are the consequences of these risks? What is the priority mechanism?

- Maintenance interventions - What are various maintenance intervention schemes in place to maintain the infrastructure and the assets in the systems?

\section{Model for futureproofing-considered infrastructure management}

A model for futureproofing-considered infrastructure management can be formed based upon the current practice and futureproofing considerations. This model considers the following:

- Diagnosis - Defines or explains the nature of the challenge in integrating futureproofing with asset management practice;

- Policies - Guiding policies to achieve a futureproofing-considered infrastructure management;

- Strategies - Containing action plans to integrate futureproofing considerations with asset management practice based upon futureproofing goals, the diagnosis and the guiding policies;

- Tactics - Coming up with futureproofing integration tactics, where opportunities arise, that will support the longterm action plans; and

- Operations - Keeping a 'value of futureproofing-considered infrastructure management' check on all operations to ensure their alignment with the futureproofing goals. 


\section{KEY BARRIERS TO INFRASTRUCTURE FUTUREPROOFING}

Barriers exist to wide adoption of futureproofing. Figure 2 provides a categorisation of key barriers to infrastructure futureproofing (i.e. a lack of understanding and a lack of compatibility in some areas, inadequate business plan, and current asset management practice that is not fit for purpose) with key elements noted in each of the categories.

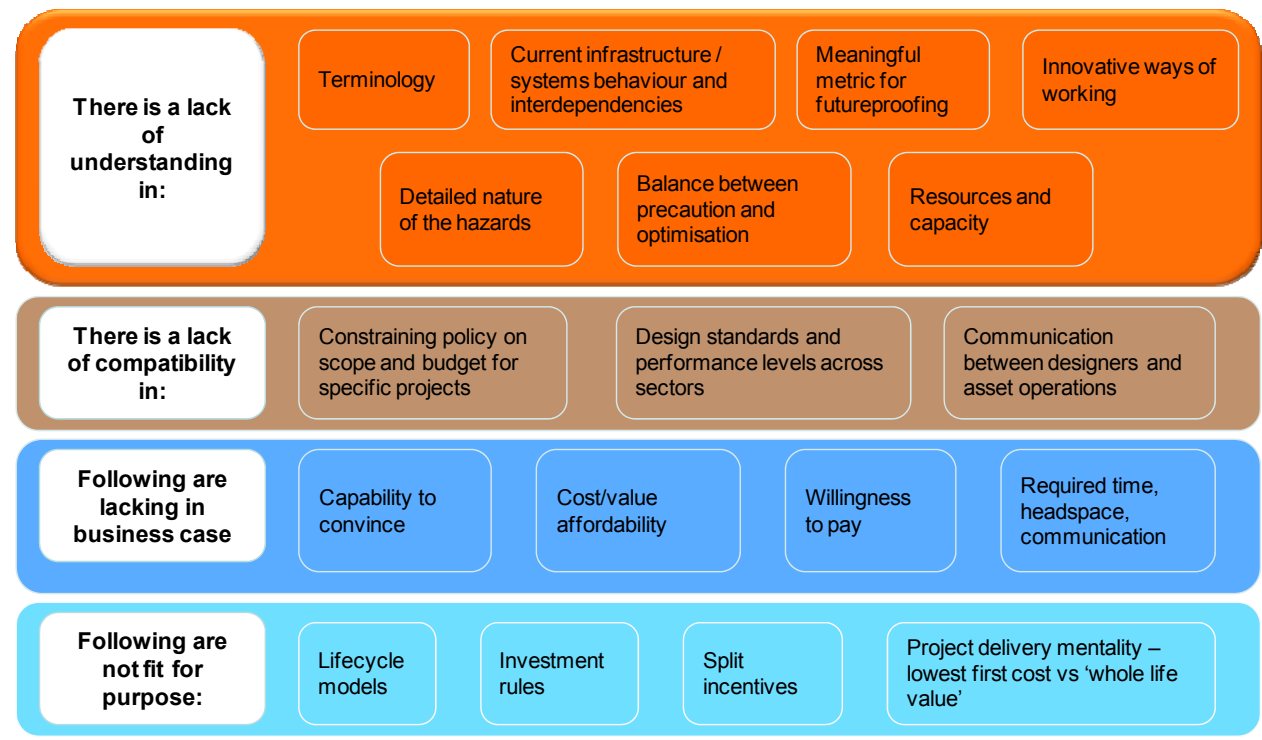

Figure 2: Key barriers to infrastructure futureproofing

\section{HOW TO INTEGRATE FUTUREPROOFING INTO ASSET MANAGEMENT PRACTICE?}

Treating futureproofing as a standalone requirement leads to marginalisation of the issue and ultimately becoming an add-on consideration. Hence, it is important that the futureproofing concepts are aligned with asset management practice and standards. Here we simply identify some issues associated with integrating futureproofing into a broader infrastructural asset management agenda.

The integration can be supported by understanding and taking care of the stakeholder requirements early on and, to fully to deliver long-lasting infrastructure, and understanding the impact of futureproofing over life cycle. Establishing and implementing futureproofing criteria across asset life cycle stages will also help integration. Planning for change earlier on and managing change in operations is key while allowing for future growth across life cycle stages.

Adopting standardized approaches to futureproofing in asset management practice will also help in integration, where Government input can be critical, through legal and regulatory standards and guidance.

Recently released asset management standard, ISO 55001:2014, considers the long term but does not specifically mention futureproofing concepts, its value and integration into asset management practice 6 (ISO 2014). However, there are possible links of futureproofing to ISO 55001. The following clauses of ISO 55001 could be extended to include requirements for futureproofing:

- Clause 4.1 (Understanding the organization and its context) and Clause 4.2 (Understanding the needs and expectations of stakeholders) can include futureproofing requirements and futureproofing criteria.

- Clause 6.1 (Actions to address risks and opportunities) can include futureproofing requirements and long term risks and opportunities.

- Clause 6.2 (Asset management objectives and plans to achieve them) can include futureproofing criteria and a model for futureproofing-considered infrastructure management.

Within the workshops run by CSIC, the value of futureproofing as part of asset life cycle management was also considered, which will be discussed in the following.

6 ISO (2014) "ISO 55001: Asset Management -- Management systems -- Requirements", 9 January 2014. 


\section{VALUE OF FUTUREPROOFING OVER ASSET LIFE CYCLE}

Futureproofing creates most value when considered during earlier asset lifecycle stages. For long term decisions, it is also important to know at what stage in the life cycle of an asset a futureproofing strategy provides the biggest value. From the CSIC futureproofing workshops, it is learnt that the asset lifecycle stages in order of accruing most value include: Operate, Maintain, Renew, Upgrade, Decommision/Reuse, Requirements, Build, Design, Installation, and Planning. Table 1 provides summary results on accruing value of futureproofing in asset management life cycle.

Table 1: Accruing value of futureproofing in asset life cycle

\begin{tabular}{|c|c|c|}
\hline Lifecycle stages & What should organisations do? & Accrued Value \\
\hline Requirements \& Plan & $\begin{array}{l}\text { - Place firm limits on asset life } \\
\text { - Specify future in requirements }\end{array}$ & $\begin{array}{l}\text { - Greater certainty/more answers/more } \\
\text { long term options } \\
\text { - Attractive financial proposition } \\
\text { - Greater R.O.R. }\end{array}$ \\
\hline $\begin{array}{l}\text { Design, Build \& } \\
\text { Install }\end{array}$ & $\begin{array}{l}\text { - Add capacities, functionalities, } \\
\text { redundancies to assets } \\
\text { - Tailor design to asset life }\end{array}$ & Negligible value gain during this stage \\
\hline Operate & $\begin{array}{l}\text { Configure to meet demand \& } \\
\text { technologies }\end{array}$ & $\begin{array}{l}\text { - Reliable performance of infrastructure } \\
\text { - Cheaper infrastructure operations }\end{array}$ \\
\hline $\begin{array}{l}\text { Maintain / Renew / } \\
\text { Upgrade }\end{array}$ & $\begin{array}{l}\text { - Predict \& prevent failures } \\
\text { - Predict maintenance interventions }\end{array}$ & $\begin{array}{l}\text { - Less reactive maintenance } \\
\text { - Safer planning \& scheduling }\end{array}$ \\
\hline $\begin{array}{l}\text { Decommission / } \\
\text { Reuse }\end{array}$ & $\begin{array}{l}\text { - Improve ability to decommission } \\
\text { safely and in an environmental } \\
\text { friendly way } \\
\text { - Extract / extend maximum } \\
\text { effective life (evidence based) }\end{array}$ & Greater residual value \\
\hline
\end{tabular}

\section{CONCLUSIONS}

The following conclusions can be drawn from the research presented in this paper:

- Infrastructure futureproofing is a concern for asset managers.

- A meaningful framework, criteria or metric for futureproofing are not formally embedded into existing options appraisal processes but are needed for effective and long term infrastructural asset management.

- Key futureproofing criteria are based on resilience, adaptability, replaceability, reusability and self-reinforcing concepts.

- Barriers exist to wide adoption of futureproofing.

- A possible infrastructure futureproofing framework has been proposed in this paper for further development.

The proposed futureproofing framework has not been tried in many industrial settings. Therefore, it is recommended to translate the framework into an actionable tool and develop a process for prioritisation of considerations for wider asset portfolios. It is also recommended to assess the applicability of the futureproofing approach to noninfrastructure asset portfolios.

\section{ACKNOWLEDGEMENTS}

The authors are thankful to the Centre for Smart Infrastructure \& Construction, Engineering and Physical Sciences Research Council (Grant EP/K000314/1), Technology Strategy Board and the industrial partners involved in the futureproofing project. The authors are also thankful to the speakers and delegates from London Underground, Costain, UCL, IBM, Crossrail, John Dora Consulting, Heathrow, Cementation Skanska, CIRIA, Network Rail, Arup, Highways Agency, Atkins, Halcrow/CH2M, Lang O' Rourke, Lend Lease, Infrastructure UK, Committee on Climate Change and University of Cambridge, who attended the CSIC workshop(s) on infrastructure futureproofing. 